\title{
Drivers of private-label purchase behavior across quality tiers and product categories
}

\author{
Philipp Noormann ${ }^{1} \cdot$ Sebastian Tillmanns $^{1}$ (D)
}

Published online: 13 October 2016

(C) The Author(s) 2016. This article is published with open access at Springerlink.com

\begin{abstract}
Private labels hold a substantial share of consumers' wallets and their popularity is still growing as they spread into various product categories and quality tiers. To determine the right branding strategy, in terms of offering uniform or different private-label brands across product categories, retailers have to know whether consumers use their private-label experience across product categories and private-label tiers. Therefore, we examine different determinants of consumers' consideration sets. We apply proneness for certain private-label tiers, product categories purchased, purchase frequency, and variety seeking as internal determinants, which contribute to consumers' knowledge and experience with private labels. Further, we use consumers' price consciousness and promotion sensitivity as external determinants, which the retailer can use to influence consumers' consideration sets in the short run. Our analyses are based on large-scale loyalty program data for a period of 24 months. In particular, we use the first 12 months to derive the determinants of consumers' share of wallets regarding different private-label quality tiers in the second half of the sample. We conduct our analyses for 12 different product categories and aggregate the results by using meta-analytic techniques. Notably, some determinants show dissimilar effects across product categories (e.g., price consciousness and promotion sensitivity), while others (e.g., private-label proneness) are rather similar. We find that consumers' general proneness for certain
\end{abstract}

Philipp Noormann and Sebastian Tillmanns contributed equally to this paper.

Electronic supplementary material The online version of this article (doi:10.1007/s11573-016-0837-1) contains supplementary material, which is available to authorized users.

Sebastian Tillmanns

s.tillmanns@uni-muenster.de

Philipp Noormann

p.noormann@uni-muenster.de

1 Institute of Marketing, University of Münster, Am Stadtgraben 13-15, 48143 Münster, Germany 
private-labels tiers leads to a propensity to purchase them in a specific category and in adjacent quality tiers. Further, we reveal that product category characteristics moderate the determinants of private-label share.

Keywords Private labels · Product categories · Private-label tiers

JEL Classification M31-marketing

\section{Introduction}

In 2015, US private-label sales reached a new record of $\$ 118.4$ billion and their share of sales reached an all-time high of $17.7 \%$ (Private Label Manufacturers Association 2016). In Europe, private labels account for \$1 of every \$3 spent on consumer packaged goods (The Nielsen Company 2014). In addition to spreading across various product categories, retailers increasingly create lines of private labels that span different quality tiers to penetrate more consumer markets (Ailawadi and Keller 2004; Geyskens et al. 2010).

Recent research has focused on the strategic question of whether retailers should opt for store-banner branding or stand-alone branding that does not link the retailer and its private-label brand (Keller et al. 2016; Schnittka et al. 2015). Retailers also have to decide whether to offer uniform private-label brands across product categories or various private-label brands for different product categories (Quelch and Harding 1996). Major supermarket chains, such as Tesco and Carrefour, often use uniform private-label branding across product categories, while most discounters, such as Aldi and Lidl, offer various private labels for different product categories. The latter branding strategy implies a broad product offering, even though a retailer predominantly offers private labels (Kumar and Steenkamp 2007); meanwhile, the former strategy allows customers to apply their product-specific private-label experience to other product categories as well (Keller et al. 2016). To determine the right branding strategy, managers need to know whether consumers use their private-label experience not only across product categories but also across private-label tiers. This research can therefore benefit managers as they make strategic decisions, because it sheds light on how consumers' private-label experience influences their purchase behavior.

In both, research and practice, private labels have long been distinguished by their inferior quality position as the cheapest option in a product category (Hansen et al. 2006; Hoch 1996). However, this distinguishing feature no longer holds. Since at least the mid-1970s, retailers have begun introducing higher tier and premium private labels (Hoch 1996) that match or even exceed national brands' quality but that still sell at a lower price (Dunne and Narasimhan 1999). They still are unlike national brands though, because private labels often appear in a wealth of product categories (Hoch 1996; Keller et al. 2016). This unique characteristic presents a challenge to research, because in the examination of private-label purchase behavior, focusing on one product category might lead to a biased understanding of 
the determinants of consumer choices (Seetharaman et al. 2005). Previous studies show that consumers' willingness to purchase private labels varies across product categories (Ailawadi et al. 2008; Sethuraman 1992) and that private labels' growth and share are unequal across product categories (Batra and Sinha 2000). Furthermore, product category characteristics function as an important moderator of the link between private-label share and store loyalty (Koschate-Fischer et al. 2014). In certain categories, strong preferences, rather than price, lead to purchases of private labels (Hansen et al. 2006). This leads some researchers to assert that the category drives private-label success even more than consumer characteristics (Ailawadi and Keller 2004; Dhar and Hoch 1997).

Because of this potentially important role of product category characteristics, previous research has issued several calls for their explicit consideration. For example, Martos-Partal et al. (2015) suggest a need for research into different product categories to explore the differential effects of the drivers of purchasing behavior of different private-label tiers and Batra and Sinha (2000) recommend examining inter-category differences in more detail. Research on cross-category differences also appears to focus mainly on manufacturer and retailer-driven factors, with only limited investigations of consumer-level factors (e.g., Hansen et al. 2006). Sethuraman and Gielens (2014) note that only a few studies examine how the effects of private-label drivers vary on the basis of product characteristics and recommend focusing on this issue in future research. In a private-label purchasing context, Hansen et al. (2006) also claim that understanding consumers' preferences and needs, beyond individual product categories, can help marketers allocate their resources more efficiently and effectively.

Although multi-tier private labels are unique from a consumer's perspective, because they span retailers' broad category and price-quality spectra, we know of no research that explicitly addresses this unique role. In our attempt to facilitate the management of multi-tier private-label portfolios across product categories, we consider three key research questions:

- Do consumers reveal similarities in their preference for private labels across categories and private-label tiers?

- Does consumers' private-label proneness for a certain private-label tier affect their private-label preference in other tiers?

- Do category characteristics moderate private-label preference factors?

In answering these questions, we examine the drivers of private-label purchasing behavior across quality tiers. Thus, we concur with prior literature in recommending that private-label tiers should be treated separately, because purchasing behavior differs across quality tiers (Martos-Partal et al. 2015). Our investigation also advances the findings from previous studies in light of the new reality of multi-tier, private-label portfolios. In particular, we build on Hansen et al.'s (2006) examination of whether private-label purchase tendencies are category- or household-specific by determining whether their findings of a private-label-prone segment of consumers can be generalized to different private-label tiers with a price-quality positioning below, similar to, or above that of national brands. In the 
context of such a multi-tier private-label portfolio, we also reveal that preferences for one private-label tier generate a spillover effect onto other private-label tiers. Managers can use these results to identify their consumers' up-selling potential.

Furthermore, our study shows that consumer choice is different across product categories and that consumers' purchasing behavior across all categories influences their choices in specific categories. We find that some drivers of private-label purchasing behavior (e.g., private-label tier proneness) reveal largely consistent effects across all product categories, while other drivers (e.g., price consciousness and promotion sensitivity) show substantial differences. In some cases, this influence is driven by the characteristics of the specific product categories we examined. In finding that consumers' purchase behaviors differ substantially across product categories, our study provides an important contribution to private-label research: we find that product categories have to be taken into account when examining consumers' private-label purchasing behavior and that researchers need to be cautious regarding the generalizability of studies that focus on a single product category or that examine product categories in aggregate.

The remainder of the article is organized as follows: we present our conceptual framework, develop hypotheses regarding the effect of intrinsically and extrinsically induced consumer behavior on private-label share, and we identify product category characteristics that might moderate the hypothesized effects. We test the hypotheses and examine the moderating effects with data from a large-scale loyalty program and a survey of product category characteristics. After outlining our results, we conclude with a summary of the findings and their implications for researchers and managers.

\section{Conceptual framework}

We define private labels as brands owned by retailers, which they market using either their own name or another name that is unique to the set of offerings (Ailawadi and Keller 2004; Kumar and Steenkamp 2007). In addition, we differentiate generic, standard, and premium private-label tiers (see also Geyskens et al. 2010; Palmeira and Thomas 2011; ter Braak et al. 2013; ter Braak et al. 2014).

Generic private labels usually offer the best price and are positioned as being of lower quality than national brands; standard private labels represent mid-price and mid-quality products; and premium private labels are positioned according to their superior quality and as close or better substitutes for national brands (Gielens 2012; Kumar and Steenkamp 2007).

When consumers choose among brands, they rely on a consideration set, which provides a task-simplifying heuristic that helps them cope with complex choice problems (Wu and Rangaswamy 2003). Consideration sets contain the specific brands that consumers seriously consider purchasing from among the subset of brands of which they are aware of. Thus, even though a brand outperforms another available brand on some relevant criteria, consumers will not purchase it if it is not in their consideration set (Andrews and Srinivasan 1995). Generally, consumers add brands to their consideration set on the basis of information that is stored in their 
memory or that they encounter during their decision-making process (Shocker et al. 1991). As Wu and Rangaswamy (2003) emphasize, consumers search both their internal memory (e.g., prior product knowledge) and external information (e.g., prices, promotions) when considering various brands.

Using a similar categorization, we examine the internal and external drivers that lead consumers to include private labels in their consideration sets. Figure 1 contains an overview of the conceptual framework we use to explain private-label share across different tiers and categories.

Similar to the categorization of internal and external information, intrinsic and extrinsic determinants might also influence brand switching behavior (e.g., Mazursky et al. 1987). Extrinsic motives, such as price discounts (Dodson et al. 1978) or promotions (Bell et al. 1999) offered by marketers, and intrinsic motives, including the consumer's internal desire to try different brands (Van Trijp et al. 1996), both induce brand switching. This categorization into intrinsic and extrinsic determinants provides management with insights regarding the question of which marketing instruments feasibly influence brand choice.

Our framework includes private-label proneness, relationship intensity, and variety seeking as internal determinants that likely influence the inclusion of private labels in consideration sets, as well as external price and promotion information, which they encounter during their product search.

Private-label proneness reflects consumers' experience with and knowledge about a retailer's private labels and the degree to which they appear in the consumers' consideration sets. Compared to private labels, national brands with large market shares are generally more popular and advertise more, such that they invoke greater awareness among consumers and are more likely to be included in consideration sets (Sethuraman 1995). Often exclusively sold by a single retailer, private labels are less widely advertised, so that consumer awareness results mainly

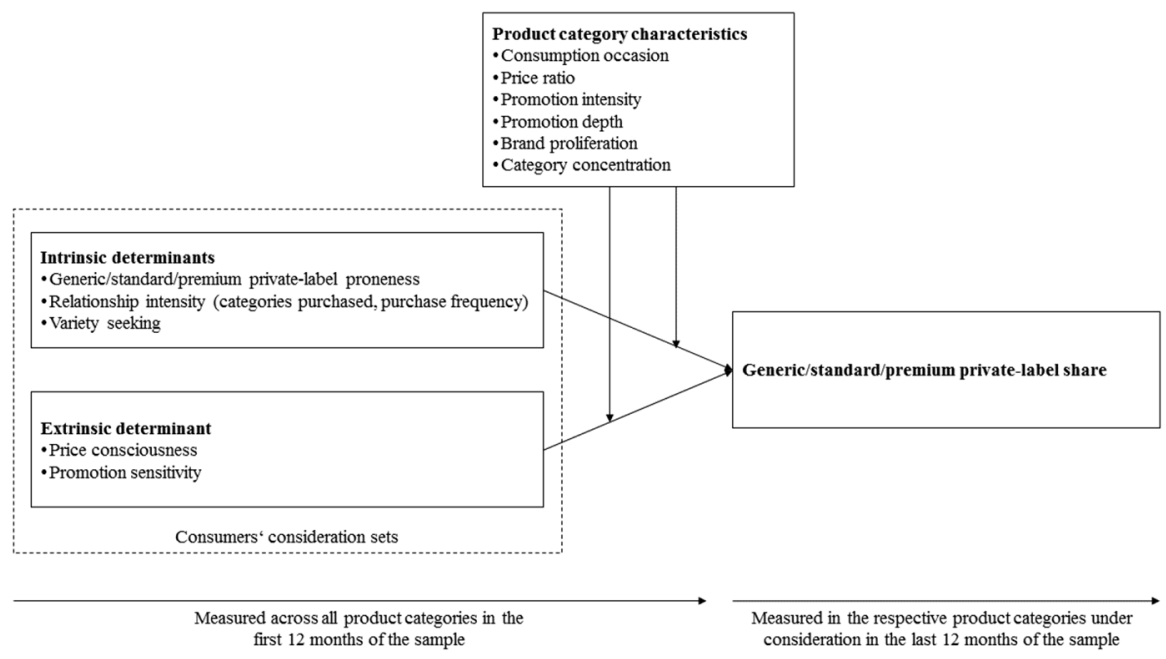

Fig. 1 Conceptual model 
from the intensity of the consumer-retailer relationship; consumers who visit a retailer more frequently encounter its private labels more regularly. We use the number of product categories purchased and purchase frequency as proxies for the relationship intensity with the retailer. Finally, variety seeking leads to brandswitching behavior and a weak disposition to stay attached to a certain brand. Switching behaviors indicate consumers' experience with some set of brands, which should provide broader brand knowledge.

With regard to the external determinants, in private-label contexts, price and promotion information are crucial, because consumers tend to switch readily from private labels to promoted national brands (Blattberg and Wisniewski 1989). That is, consumers often include promoted brands in their consideration sets (Wu and Rangaswamy 2003). Therefore, we rely on price consciousness and promotion sensitivity as drivers of private-label purchasing behavior, since these measures indicate the degree to which consumers are influenced by external information in their decision making. Price-conscious consumers focus on low prices (KoschateFischer et al. 2014) and are more likely to switch from a national brand. This motive might have mixed effects in multitier private-label portfolios-in particular, it should encourage repurchases of lower tier private labels. However, the effects of price consciousness on standard and premium private labels might differ because they tend to follow a pricing strategy that is more similar to that of national brands. Marketers use promotions to encourage consumers to switch, whereas promotion sensitivity determines consumers' responsiveness to these efforts. Since private labels are rarely subject to promotions, promotion sensitivity might prompt consumers to switch from private labels to national brands.

We consider a unique feature of private labels - namely, that they are available in various categories and quality tiers, unlike national brands. Because context-specific consideration sets vary across product categories, private labels might appear in many different consideration sets, whereas national brands generally appear only in one or a few. Therefore, product category characteristics might have a critical role in determining consideration sets and studying product category differences might help explain variations in private-label shares across categories (Sinha and Batra 1999).

Yet consumers exhibit similar preferences for private labels across product categories (Hansen et al. 2006), which might reflect stimulus generalization and categorization theory. Stimulus generalization refers to the degree to which a response conditioned to a specific stimulus is also evoked by similar stimuli (Till and Priluck 2000). It is therefore based on classical conditioning, whereby an unconditioned stimulus (e.g., a brand) gets paired with a conditioned stimulus (e.g., a pleasant image), and the link then assigns some meaning to the brand that evokes favorable responses. Generalization means that a stimulus that resembles the conditioned stimulus evokes a conditioned response that is similar to the response evoked by the original conditioned response. As Till and Priluck (2000) show, brand attitudes can transfer to products with similar brand names, in the same and different product categories, and these effects even persist over time. Stimulus generalization thus is relevant to brand extensions and private-label marketing strategies, although it might be limited to products that are extremely similar to the original. 
We consider the application of this theory to private labels, which offer different quality tiers across product categories. Therefore, we question, whether consumers abandon their traditional assignment of all private labels to a single mental category or whether they construct different mental categories for each quality tier (Szymanowski and Gijsbrechts 2012). In the latter case, stimulus generalization might not be sufficient to explain private-label purchasing behavior, because in these different quality tiers, the boundaries between national brands and private labels, especially standard or premium versions, are less well defined. Therefore, we also rely on fuzzy set theory (Kaufmann 1975; Zadeh 1965), which replaces clear membership versus non-membership categories with the idea of gradually increasing memberships (Hruschka 1986), such that no clear boundaries exist between members and non-members of a fuzzy set and marginal members exhibit different properties than prototypical members (Smithson 2012; Viswanathan and Childers 1999). According to Wu and Rangaswamy (2003), the fuzzy set approach is especially suitable for modeling consideration sets, in which consumers consider each alternative to a greater or lesser extent. Given this claim, we posit that consumers define prototypical private labels as the ones that are similar to the generic versions, offering appealing prices and having a lower quality position relative to national brands. Consumers then might form different mental categories for the standard and premium private labels, which have higher price and quality levels and thus are less distinct from national brands. Accordingly, consumers' consideration sets might become fuzzy, and certain private-label tiers might be considered to a greater or lesser extent compared to national brands.

Even though consumers use different consideration sets for different product categories (Viswanathan and Childers 1999), we suggest that these consideration sets are not completely independent from one another, because some product categories share similar characteristics. The inclusion of a private-label product within a category-specific consideration set therefore might be fuzzy (i.e., capable of influencing other categories rather than being bound within strict category borders). Thus, private labels could be included simultaneously in several consideration sets that share similar product category characteristics. This prediction aligns with Szymanowski and Gijsbrechts's (2012) assertion that consumers' quality beliefs can be influenced by their private-label experiences with the same retailer in other categories. The authors claim that future studies should investigate such influences, which might have important implications for the rollout of private labels across different product categories.

To test our conceptual framework, we chose an empirical approach to account for the fuzziness of private labels in terms of their categorization and inclusion in consideration sets across different product categories. Notably, in our cooperation partners' database with purchase information from several million customers, less than $0.01 \%$ of all customers never bought private labels in the period we examined in this study. Therefore and in line with fuzzy set theory, we suggest that the degree to which customers buy private labels is a more appropriate measure to model private-label purchasing behavior than distinguishing customers in either nonpurchasers or purchasers of private labels. Accordingly, we derive private-label proneness toward a certain quality tier as the share of a household's spending on that 
tier in the first 12 months of our sample. The measure is based on all categories in which that private-label tier is available. Private-label proneness toward a certain private-label tier is fuzzy according to the degree (i.e., share) to which it is included in a consumer's consideration set across all categories. We consider a household's shares of certain private-label quality tiers in certain product categories during the last 12 months of our sample as dependent variables. By comparing the effects of internal and external determinants on private-label share, we gain insights into the degree to which consumers treat different private-label tiers as one or multiple mental categories. This also represents a response to Ailawadi and Keller's (2004) call for research into the degree of flexibility with which consumers form mental categories for retail brands.

\section{Determinants of private-label tier share}

\subsection{Intrinsic determinants}

\subsubsection{Private-label proneness}

While national brands often are available in only one product category, private labels are mostly available in various product categories. Accordingly, consumers form category-specific consideration sets that have different brand compositions. We suggest that the degree to which consumers have been prone to prefer a specific private-label tier across all product categories positively influences the degree to which it is included in the consideration set of a specific private-label tier in a specific product category regarding future purchase decisions. Our hypotheses draw on categorization theory, which suggests that people assign objects to different cognitive categories according to their perceived similarity, in an attempt to improve their information processing (Mervis and Rosch 1981). Categorization helps to assign meaning to unknown objects, so that people can make inferences and evaluative judgments, using their knowledge about the other objects in the same category (Cohen and Basu 1987). Although Till and Priluck (2000) find that brand attitudes can be transferred to products with a similar brand name in the same or different product categories, their finding suggests that this stimulus generalization occurs only with very similar products. Whether general private-label proneness regarding a specific private-label tier necessarily leads to a higher private-label share in that tier in a specific product category in the future is therefore questionable.

In line with our suggestion, Erdem et al. (2004) note the importance of consumer learning in consumers' private-label brand and national brand choices, such that consumers' perceptions about brands and product quality change when they learn about different products through their consumption experiences. This learning leads to more precise and reliable information and can, in turn, reduce the perceived risk of product choice. Similarly, familiarity with a private-label brand might drive private-label purchases because it allows consumers to rely less on extrinsic cues in their quality evaluations (Richardson et al. 1996). They then exhibit greater private- 
label brand proneness and perceive less quality variation between national and private-label brands. In line with this finding, Keller et al. (2016) and Schnittka et al. (2015) claim that using a private label in several product categories increases consumers' awareness, experience, and familiarity with a private label. As a way to increase private-label familiarity, Sprott and Shimp (2004) identify product sampling of high-quality, private-label offers as an effective way to improve consumers' private-label quality perceptions.

Based on the findings of previous research, we propose that private-label proneness has a positive effect on the share of expenditures on private labels. We therefore state:

H1 Consumers who were more prone to buy (a) generic, (b) standard, and (c) premium private labels across all product categories purchase higher shares of these private-label tiers (compared to national brands) in a given product category.

Categorization implies that consumers classify two brands with similar characteristics, which are distinguishable from the characteristics of other brands, into the same subcategory (Nenycz-Thiel and Romaniuk 2009). In their memories, consumers retain schema-like knowledge structures about products and brands. If a novel brand appears unlike existing brands, consumers create a new subcategory (Pan and Lehmann 1993). The more typical a stimulus, the more accurately and quickly it can be categorized into an existing category (Mervis and Rosch 1981). Therefore, the similar positioning of two private labels in different quality tiers should lead consumers to put them into the same mental category. The extent of similarity might determine the degree to which consumers extrapolate their quality tier experience from one tier to another when they build up their consideration sets. Nenycz-Thiel and Romaniuk (2009) indicate that private labels generally form a distinctive subgroup in consumers' memory because their attributes-including their low prices, low perceived quality, and potential for risk-appear unlike those of national brands. These distinctions clearly apply to traditional private-label positioning, but whether they hold for standard and premium private labels, whose market positioning and value proposition are similar to national brands, is questionable. However, if this is the case, positive associations with one privatelabel tier could transfer to others.

According to stimulus generalization and categorization theory, products with highly similar price positioning and brand names (e.g., retailer's name on different private-label tiers) likely constitute the same brand category. Therefore, beliefs about quality and functions may transfer across similar private-label tiers. In line with research indicating that brand switching is more likely across adjacent tiers (Sethuraman and Cole 1999), we also predict that consumers' proneness to buy a private-label tier does not exert strong influence on expenditures on another, distant private-label tier. For example, proneness to buy premium private labels should not drive generic private-label purchases. However, this proneness could enhance purchase behaviors in the adjacent standard-private-label tier. Thus, we offer specific hypotheses for each tier: 
$\mathrm{H} 2 \mathrm{a}$ Consumers who were more prone to buy generic private labels across all product categories purchase higher shares of standard private labels (compared to national brands) in a given product category.

$\mathrm{H} 2 \mathrm{~b}$ Consumers who were more prone to buy standard private labels across all product categories purchase higher shares of generic private labels (compared to national brands) in a given product category.

$\mathrm{H} 2 \mathrm{c}$ Consumers who were more prone to buy premium private labels across all product categories purchase higher shares of standard private labels (compared to national brands) in a given product category.

$\mathrm{H} 2 \mathrm{~d}$ Consumers who were more prone to buy standard private labels across all product categories purchase higher shares of premium private labels (compared to national brands) in a given product category.

\subsubsection{Relationship intensity}

In general, consumers cannot buy a certain private label from different retailers. Thus, their usage is exclusively linked to the consumers' relationship intensity with a certain retailer and consumers who frequently purchase at this retailer develop familiarity with its private-label assortment (Richardson et al. 1996). Sethuraman and Gielens (2014) state that purchase frequency is a crucial driver of private-label share and that it is even more important than basket expenditures in terms of building private-label volume. Ailawadi et al. (2008) also note that spending a lot of time and money at a retailer enhances consumers' familiarity with its private labels across categories and increases their private-label proneness. Analogously, loyalty toward a certain retailer increases familiarity with its private-label portfolio, such that loyal consumers are more prone to purchase the retailer's private labels (e.g., Ailawadi et al. 2001, 2008; Manzur et al. 2011). Behavioral loyalty can also lead consumers to purchase products in multiple categories (Reinartz et al. 2008).

We therefore use the number of product categories purchased and purchase frequency as measures of relationship intensity, with the assumption that greater intensity increases consumers' familiarity with a retailer's private-label portfolio. Thus, consumers who exhibit a strong relationship with the retailer are more likely to include its private-label brands in their consideration sets. We therefore posit:

H3 Consumers who bought products in more product categories purchase higher shares of (a) generic, (b) standard, and (c) premium private labels (compared to national brands) in a given product category.

H4 Consumers who bought more frequently purchase higher shares of (a) generic, (b) standard, and (c) premium private labels (compared to national brands) in a given product category. 


\subsubsection{Variety seeking}

Variety seeking represents a motivation-related measure, reflecting an exploration orientation that drives consumers' behavior toward private labels (Ailawadi et al. 2001). We suggest that variety-seeking behavior extends consumers' consideration sets because it leads to an achievement of knowledge about a variety of brands. Yet its effect on private-label purchasing behavior is not clear. Some researchers argue that consumers with a high need for variety are less sensitive to product prices and more prone to purchase national brands or premium private labels (Baltas 1997; ter Braak et al. 2014). Ailawadi et al. (2001) similarly suggest that variety-seeking consumers are less prone to use private labels because regularly using store brands fails to provide variety. Nevertheless, they find that variety seeking relates positively to private-label use - a finding they explain by positing that variety seekers use private labels for a change of pace. Another explanation comes from Fader and Lodish's (1990) argument that variety-seeking behavior is associated with a desire for relatively low prices, which reduce the risk and cost of switching brands. Therefore, we posit that variety-seeking consumers are more prone to generic and standard private labels, whereas premium labels are negatively affected by variety-seeking behavior. That is:

H5 Consumers who were more prone to variety-seeking behavior across all product categories purchase (a) higher shares of generic, (b) higher shares of standard, and (c) lower shares of premium private labels (compared to national brands) in a given product category.

\subsection{Extrinsic determinants}

\subsubsection{Price consciousness}

The majority of consumers purchase private labels to save money (The Nielsen Company 2014), such that Koschate-Fischer et al. (2014) identify price consciousness as a key consumer characteristic, which explains private-label shares. Several studies affirm that category price consciousness drives private-label purchases (Batra and Sinha 2000; Hansen et al. 2006; Hoch 1996; Sinha and Batra 1999).

However, the effect of price consciousness likely differs across private-label tiers. According to Martos-Partal et al. (2015), price-sensitive consumers prefer generic and standard private labels over national brands, but less price-sensitive consumers prefer premium store brands. We therefore posit that price consciousness has a positive effect on the shares of generic and standard private labels. Consumers are more likely to include them in their consideration sets because these private labels help them to save money. We assume a negative influence on the share of premium private-label brands because their pricing is less distinct from national brands and often even higher. We hypothesize:

H6 Consumers who were more price-conscious across all product categories purchase (a) higher shares of generic, (b) higher shares of standard, and (c) lower 
shares of premium private labels (compared to national brands) in a given product category.

\subsubsection{Promotion sensitivity}

Private-label brand buyers are not always seeking promotions, even when they are price sensitive (Ailawadi et al. 2001; Burton et al. 1998; Martos-Partal et al. 2015). Rather, Ailawadi et al. (2001) assert that private-label brand purchases and promotion use are associated with different psychographics. With a cluster analysis, they identify four consumer segments: deal-focused, private-label-focused, deal and private-label users, and non-users of private-label brands and deals. Consumers who search for price cuts and special offers generally are not prone to buying privatelabel brands (Baltas et al. 1997), which consistently offer lower prices and are not promoted as often as national brands. Their consideration sets are predominantly determined by national-brand promotions. Thus, price discounts generally move consumers from lower to higher quality brand offerings, rather than the other way around (DelVecchio and Heath 2008). Consumers of lower quality brands are more attracted to price-discounted, higher quality brands than consumers of higherquality brands are attracted to price-discounted, lower quality brands. This effect is known as asymmetric price competition (DelVecchio and Heath 2008).

Accordingly, Martos-Partal et al. (2015) posit that promotion sensitivity is associated with lower probabilities of purchasing generic private labels, relative to the probability of purchasing standard and premium store brands. However, they actually found no significant effect on private-label purchasing behavior. We suggest that this finding might stem from the divergent effects of promotion sensitivity across categories.

Still, we expect promotion sensitivity to exert negative effects on private labels across all quality tiers, such that consumers who have reacted more often to price promotions in the past are more likely to purchase national brands. Hence, the following is hypothesized:

H7 Consumers who were more promotion-sensitive across all product categories purchase lower shares of (a) generic, (b) standard, and (c) premium private labels (compared to national brands) in a given product category.

\subsection{Product category characteristics}

\subsubsection{Price ratio between private labels and national brands}

Sethuraman and Gielens (2014) and Steenkamp and Geyskens (2014) find that a higher price gap between private labels and national brands generally is associated with a higher private-label share. Consumers are willing to pay a price premium for national brands, but the price gap can drive them to switch to private labels (Steenkamp and Geyskens 2014). Price-conscious consumers are more prone to buy private labels (e.g., Burton et al. 1998; Hansen et al. 2006), but again, this proneness might vary across private-label tiers because the price gaps with national brands 
differ. Dhar and Hoch (1997) find price gaps of 20-60\% between private labels and national brands across categories. Premium private labels are often priced above national brands, whereas the direction of the price difference between mid-tier (standard) private labels and national brands is less certain. Therefore, examining price differences across product categories and private-label tiers should contribute to a better understanding of the effect of price consciousness on private-label share.

\subsubsection{Promotion intensity}

Promotions aim to attract consumers' attention at the point of purchase (Lamey et al. 2012), where many purchase decisions take place in grocery contexts. Such promotions generally are associated with national brands and therefore likely affect private-label shares. Accordingly, Steenkamp and Geyskens (2014) find a negative relationship between promotion intensity and the share of private labels in a category. Dhar and Hoch (1997) also show that private labels suffer lower market shares in categories that have a high promotion intensity because they lose their low price advantage relative to national brands; Raju et al. (1995) even recommend not introducing private labels in such categories. Similarily, Lal (1990) finds that promotions are effective instruments for limiting the growth of private labels or even driving them out of the market. Conversely, intense use of promotions might increase consumers' price consciousness, which could harm national brands in the long run (Mela et al. 1997). Such ambiguous findings indicate that promotion intensity is an important product category characteristic that might moderate the effects of the determinants of private-label share.

\subsubsection{Perceptions as a hedonic product category}

Several studies emphasize the role of hedonic product category characteristics. For example, Ailawadi et al. (2008) assume that the relationship between private-label share and the share of wallet for a specific retailer might be stronger in hedonic product categories (e.g., desserts). According to Sethuraman and Cole (1997), national brands are more likely to charge a price premium if they offer products that have more hedonic than functional characteristics.

These trends likely arise because the usage experiences for hedonic categories and the emotional arousal that accompanies them, establish their categorization. For example, in the context of food, the pleasure is predominantly related to taste experiences and extraordinary indulgence. Thus, in hedonic categories (e.g., sparkling wine or chocolate), consumers tend to focus on quality in terms of a special taste but give less consideration to a low price in making a purchase decision, because low price is considered as a signal of lower quality (Kapferer and Laurent 1993). In hedonic categories in general, price is less decisive, and quality is more so, than it is in utilitarian categories (Zielke and Dobbelstein 2007). Although traditional private labels might be purchased primarily for functional reasons (Ailawadi et al. 2008; Kumar and Steenkamp 2007), the rise of premium private labels and their expansion across product categories suggest that they increasingly appear in hedonic product categories, too. Nevertheless, hedonic products often bear 
a social risk, because they are often consumed in the company of others (Raghunathan and Corfman 2006) and their consumption can be associated with the consumer's own personality or status (Noble and Walker 1997). In such public consumption situations, well-known brand names can help deter the risk of others' negative evaluations (Bearden and Etzel 1982). Consequently, consumers might be less prone to buy private labels than national brands in hedonic product categories.

We thus question whether the drivers of purchase behavior, as identified for traditional private labels in rather functional categories, have similar effects for private labels in hedonic product categories.

\section{Empirical study}

\subsection{Data}

\subsubsection{Purchasing data}

We obtained purchasing data from 40,000 participants in a loyalty program of a major grocery chain in Germany over a period of 2 years, during which time the consumers accounted for 3.9 million purchase incidents. Several authors recommend the use of purchasing data for studying private labels: Batra and Sinha (2000) suggest that scanner data can overcome the disadvantages of survey data (e.g., inaccurate recall) and Richardson et al. (1996) argue that behavioral measures of private-label proneness provide more confidence in the findings than self-reported data do.

Participants were selected at random and had made at least one purchase every 2 months throughout the entire observation period. We thus excluded occasional consumers, who probably are less familiar with the grocery chain's private-label brands.

Our cooperative grocery partner offers generic, standard, and premium privatelabel brands. We only considered product categories for our category-specific analyses, which are sufficiently large to include all three tiers. In accordance with ter Braak et al. (2014), we also excluded categories in which products do not feature brand names and consumers cannot distinguish products of different brands (e.g., fresh vegetables). Therefore, we considered butter, pralines, mayonnaise and mustard, desserts, edible oil, dry fruits, dessert sauces and red fruit jelly, frozen fish, vinegar, frozen venison and poultry, ice-cream, and chocolate as product categories.

\subsubsection{Survey data}

We conducted a survey of 96 students to assess general perceptual differences related to the examined product categories in terms of their consumption occasion (hedonic vs. functional). Therefore, each participant received exemplary product pictures from each product category, with the brand names hidden. We adapted a single-item measure from an established scale because the participants had to evaluate several categories, and we assumed that providing answers to the same 
multiple items every time would likely exhaust them, resulting in less reliable data. Previous studies that also use single-item measures, note their generally high validity and reliability (e.g., Chitturi et al. 2008; Homburg et al. 2015).

\subsection{Procedure and measures}

\subsubsection{Perceptual product category characteristics}

We conducted a repeated-measures analysis of variance (ANOVA) regarding the degree to which the purchase occasion of a product category is perceived as hedonic, using the question, "Please indicate when you normally use the following product categories"; responses ranged from $1=$ "for routine need, practical purposes" to $7=$ "for pleasure, fun, enjoyment" (Wakefield and Inman 2003). Because Mauchly's test indicated that the assumption of sphericity had been violated, we report the corrected degrees of freedom (rounded to whole numbers) using the Greenhouse-Geisser correction. The purchase occasion differed significantly across product categories $(\mathrm{F}(8)=58.16$; $p<0.001)$. We applied Bonferronicorrected post hoc comparisons to specify whether pairs of product categories differed in their examined characteristics (see Table 1).

\subsubsection{Structural product category characteristics}

Table 2 contains an overview of key category characteristics. To derive the promotion intensity in a given category, we divided the number of promoted items sold by the total number of items sold. We calculated the promotion depth as the weighted average of promotional price cuts in a given category (see Lourenço et al. 2015, for a similar procedure). As a measure of brand proliferation, we took the number of available brands in a given category into account. Furthermore, we measured the category concentration as the squared market share of the top three national brands in a given category (we also reported private-label market shares for descriptive purposes). In a similar way, Nijs et al. (2007) derive category concentration as the cumulative market share of the top three brands. We determined the price ratio between the different private-label tiers and national brands by dividing the average private-label price by the average national brand price in each category. For private labels priced below the national brand level (e.g., in the generic tier), a small price difference between private labels and national brands produces a high price ratio, whereas a big price difference means a low price ratio. The meaning of the ratio is opposite for private labels priced higher than national brands (e.g., in the premium tier), such that a big price difference between private labels and national brands means a high price ratio, while a small price difference means a lower price ratio.

\subsubsection{Private-label purchasing behavior}

To identify the drivers of private-label purchasing behavior, we consider a privatelabel hierarchical quality-tier structure and split the sample into two periods of 12 months each. For the first 12 months, we derive predictors of private-label 


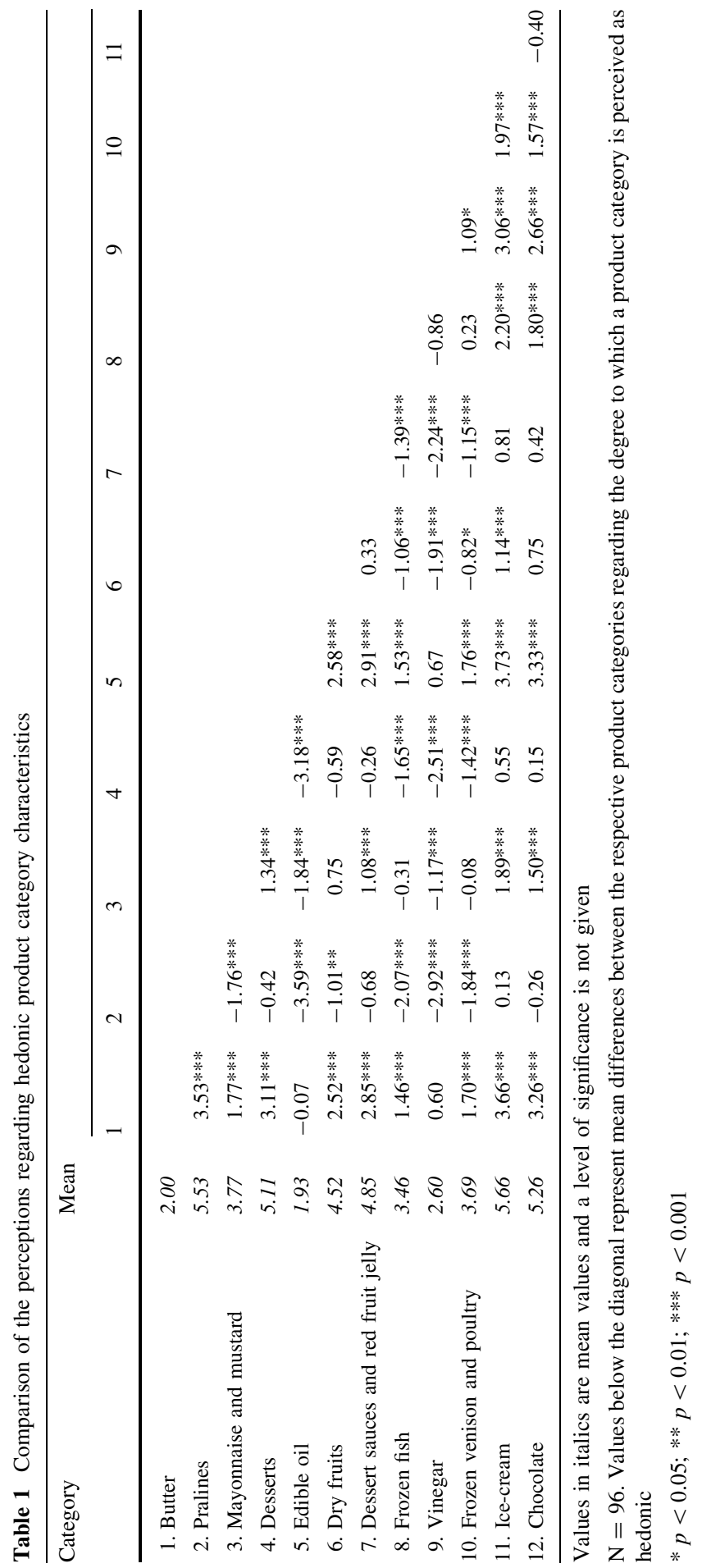




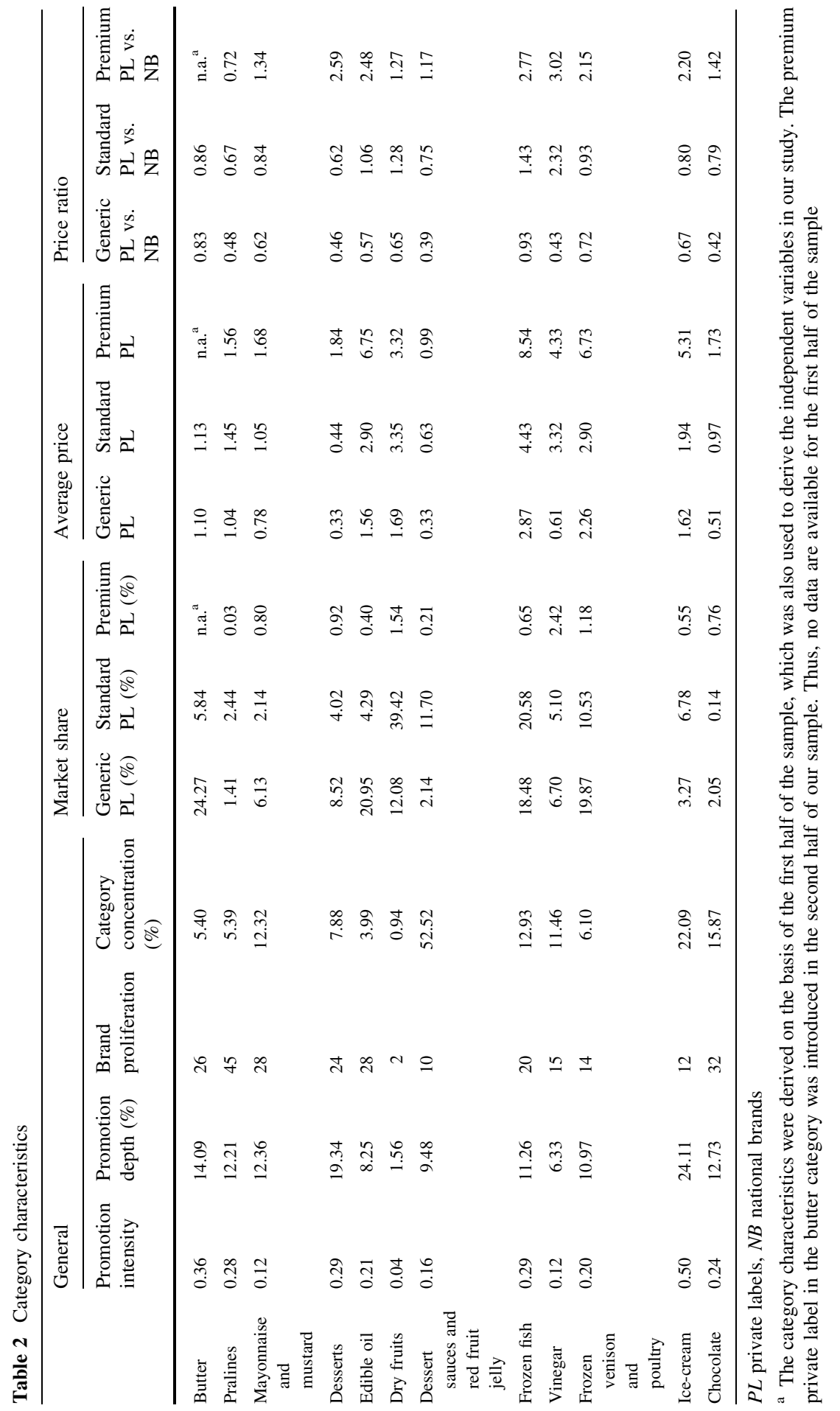


purchasing behavior and moderating category characteristics; for the data from the last 12 months, we obtain the shares of private-label expenditures per tier in a category as dependent variables. Consistent with Ailawadi et al. (2008) and Koschate-Fischer et al. (2014), we use annual data because monthly variations in purchase behavior are not likely to reflect a general propensity to buy private labels.

As independent variables, we include proneness to buy (generic, standard, and premium) private labels. We define these measures as the household's generic, standard, or premium private-label spending in terms of the percentage of its total spending on categories in which the retailer offers a product in that respective private-label tier. We also obtain the number of categories purchased by a household. For purchase frequency, we count the number of purchase incidents per household in our sample. Variety seeking reflects the number of distinct stockkeeping units (SKUs) a household has purchased in a given category. For our measure of price consciousness, we adapted Koschate-Fischer et al.'s (2014) approach and derived the average price that individual households paid in each category and divided it by the average price that all households paid in these categories. We weighted this measure by the share of the households' spending in the category, compared to total spending, and inverted it. If a household did not buy products from a certain category in our sample during the first 12 months, we did not include this category when determining its price consciousness. Specifically, the following formula produced our price consciousness measure:

$$
\text { Price consciousness }=\frac{1}{\sum_{c=1}^{C} \frac{p_{c}}{\frac{\sum_{i=1}^{l} p_{c i} x_{c i}}{\sum_{i=1}^{l} x_{c i}}} \frac{p_{c} x_{c}}{\sum_{c=1}^{C} p_{c} x_{c}}},
$$

where $\mathrm{p}_{\mathrm{c}}$ indicates the average item price paid in a category $\mathrm{c}$, and $\mathrm{x}_{\mathrm{c}}$ is the number of items bought in category $\mathrm{c}$ by household $\mathrm{i}$. We also adjusted the measure of general price consciousness for package size. Because of the computational complexity, we limited the number of product categories considered for this measure to 62. Finally, we derive the independent variable promotion sensitivity from the share of expenditures associated with promotions across all the categories. We also include two control variables: family household is a binary variable that indicates whether the household bought any baby-care products, whereas weekend purchasers measures the household's share of expenditures that occurred on weekends during the study period.

In our sample, with $\mathrm{i}=1, \ldots, \mathrm{N}$ households, households make a purchase by choosing from among generic, standard, and premium private labels, as well as national brands. Expenditures for each of the alternatives therefore are some fraction (or share) of total household expenditures. Accordingly, $\mathrm{j}=1, \ldots, \mathrm{J}$ represents the four alternative household brand choices, corresponding to generic, standard, and premium private labels and national brands, respectively. We use $\pi_{i j}$ to denote the share of a household's expenditures on one of the alternative brands $j$. The nature of our data requires that $\sum_{j=1}^{J} \pi_{i j}=1$ for all households i, and 0 $\leq \pi_{i j} \leq 1$. 
We apply a fractional multinomial logit model to reveal the household's share of expenditures on private-label tiers and national brands. To estimate our multinomial fractional logit models, we used the Stata FMLOGIT module by Buis (2008), which is based on a fractional logit approach by Papke and Wooldridge (1996). In a similar setting, Martos-Partal et al. (2015) apply a multinomial fractional model to examine how the benefits that consumers seek, explain the private-label share of different tiers at two different grocery chains. Further, we explain consumers' consideration sets with the fuzzy set approach, for which fractional regression models have been identified as suitable (Ragin 2009).

The functional form of our multinomial logit incorporates our considerations (Mullahy 2015), such that

$$
\pi_{i j}=\frac{e^{z_{i j}}}{\sum_{j=1}^{J} e^{z_{i j}}},
$$

where

$$
\begin{aligned}
z_{i j}= & \beta_{0}+\beta_{1} \text { generic PL } \text { proneness }_{i j}+\beta_{2} \text { standard PL proneness } s_{i j} \\
& +\beta_{3} \text { premium PL proneness }_{i j}+\beta_{4} \text { categories purchased } i j \\
& +\beta_{5} \text { purchase frequency }_{i j}+\beta_{6} \text { variety seeking }_{i j}+\beta_{7} \text { price consciousness }_{i j} \\
& +\beta_{8} \text { promotion sensitivity }_{i j}+\beta_{9} \text { family household }_{i j} \\
& +\beta_{10} \text { weekend purchasers } \\
&
\end{aligned}
$$

For the multinomial logit estimator, the parameter $z_{j}$ must be set to 0 for one category $\mathrm{j}$ for model identification. That is, one of the brand choices has to be set to 0 and therefore serves as the reference for comparison with the other brand alternatives. Setting one alternative to 0 leads to $e^{z}=e^{0}=1$, resulting in the following relationships:

$$
\begin{gathered}
\pi_{i j}=\frac{e^{z_{i j}}}{1+\sum_{j=1}^{J-1} e^{z_{i j}}} \text { for the brand under consideration, and } \\
\pi_{i 0}=\frac{1}{1+\sum_{j=1}^{J-1} e^{z_{i j}}} \text { for the reference brand. }
\end{gathered}
$$

In our hypotheses, we always use national brands as the reference brands, although to identify our model fully, we also provide results when we use different private-label tiers as reference brands.

We estimated separate multinomial fractional logit models for each category, which are available in the Web Appendix. The Wald tests indicated a high and significant global fit for all estimated models. The number of regular consumers in a given category varied from 6509 to 30,434, so a comparison of effects across categories is not very feasible. Instead, to achieve equal sample sizes across categories, we drew random samples for each category. Therefore, we removed the honey category because only 6509 consumers bought products in this category-far fewer than in the next-smallest category (i.e., 11,103 ice cream consumers). We 
then drew a random sample of 11,000 consumers for each remaining category. Furthermore, in line with Hansen et al. (2006), we included the share of expenditures made during the weekend and whether a household purchased babycare products as controls, because we had no sociodemographic information about the consumers in our sample. The variance inflation factors do not exceed 1.97, so multicollinearity is not likely to be an issue in our model.

To reveal similarities and differences in the drivers of private-label purchasing behavior across product categories as well as the potentially moderating influences of category characteristics, we adopt procedures commonly applied in metaanalyses to compile the results of different research studies. Similar to Sethuraman (2009), we compute empirical support scores (E-scores) as summary statistics of the effects' directions across categories. To calculate the E-scores for each independent variable, we subtract the number of categories with a significant negative effect from the number of categories with a significant positive effect. Thus, a positive (negative) E-score indicates that an independent variable mostly has positive (negative) significant effects across categories. Furthermore, we derive an E-score ratio to measure the consistency of effects across categories. To compute this E-score ratio, we divide each E-score by the total number of categories. An E-score ratio close to or equal to 1 indicates that the independent variable under consideration mostly has equally directed, significant effects across all categories. Meanwhile, an E-score ratio close to 0 indicates mostly non-significant or differently directed effects.

Next, we derive meta-analytic z-statistics (Rosenthal 1991) to determine whether the effects differ significantly from 0 across all categories. Gielens (2012) similarly applies meta-analytic z-statistics to the overall effects of new products introduced by national brands and private labels on category sales. The following formula was used to produce the $\mathrm{z}$-statistics for our respective independent variables:

$$
z_{j}=\frac{\sum_{c=1}^{C} z_{j c}}{\sqrt{C}},
$$

where $\mathrm{c}=1, \ldots, \mathrm{C}$ represents the product categories under consideration, and $z_{j}$ is the $\mathrm{z}$-statistic of the independent variable $\mathrm{j}$ across categories, obtained by dividing the respective $\beta_{j}$ by the standard error $s e_{j}$. We provide the results of these estimations in Tables 3 and 4 .

As an illustrative example of our proceeding, we refer to the effect of the independent variable number of categories purchased on generic private-label share in Table 3. The variable reveals positive significant effects in seven categories, a negative significant effect in one category, and no significant effects in four categories. Accordingly, the E-score equals 6 ( 7 positive -1 negative significant findings). The E-score ratio is .5 [E-score divided by the number of categories (i.e. $6 / 12)$ ], which indicates that the number of categories purchased does not reveal consistent effects across all categories. Still, because most effects across all categories are positive and significant, we find a positive and significant $\mathrm{z}$-score (i.e., overall effect). 


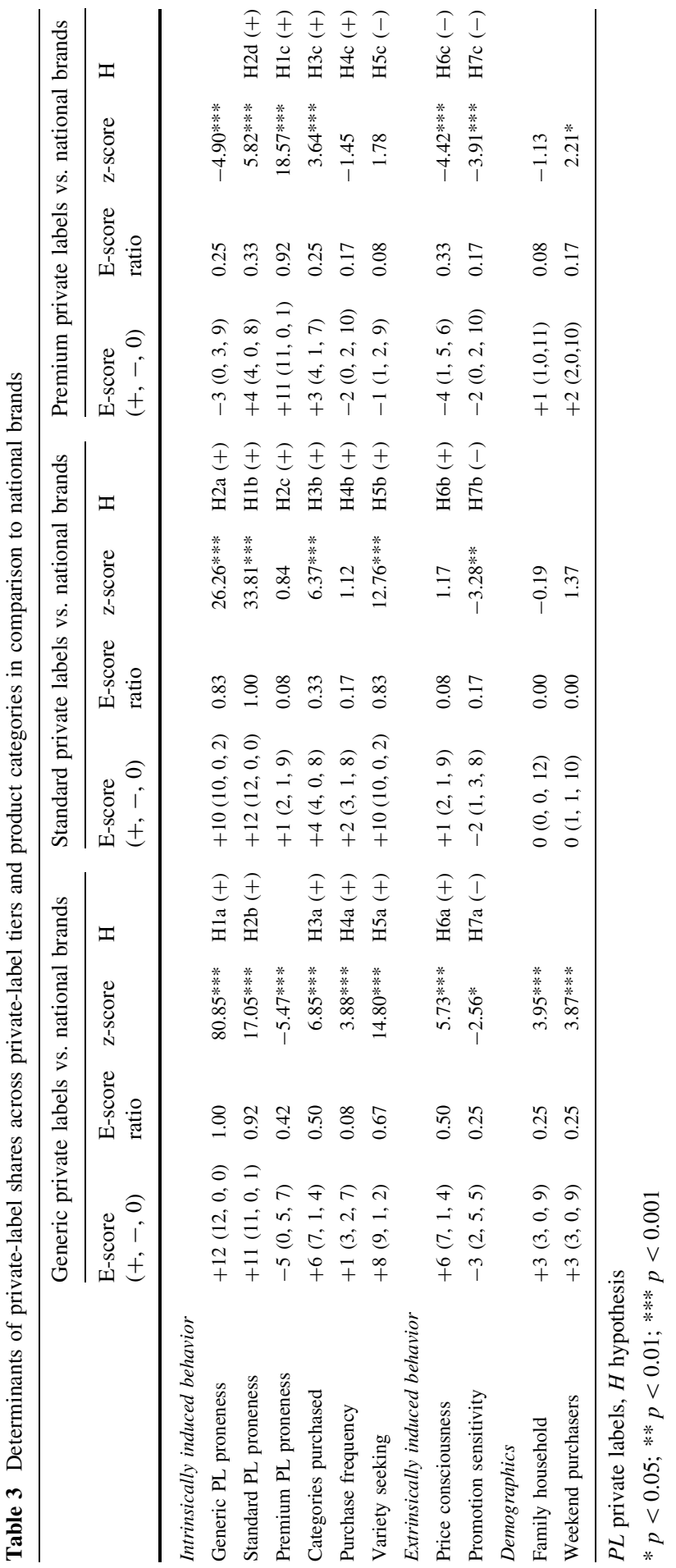




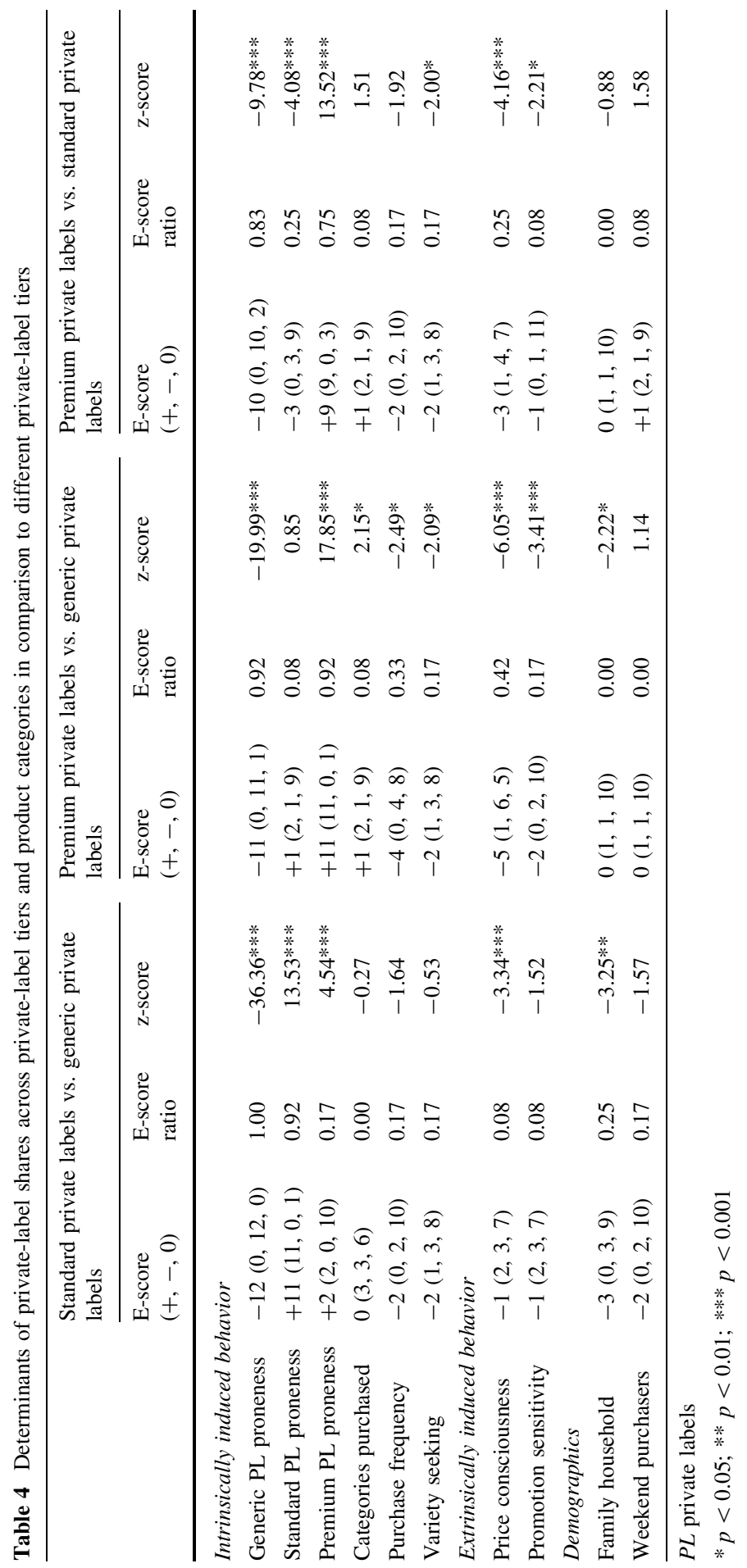




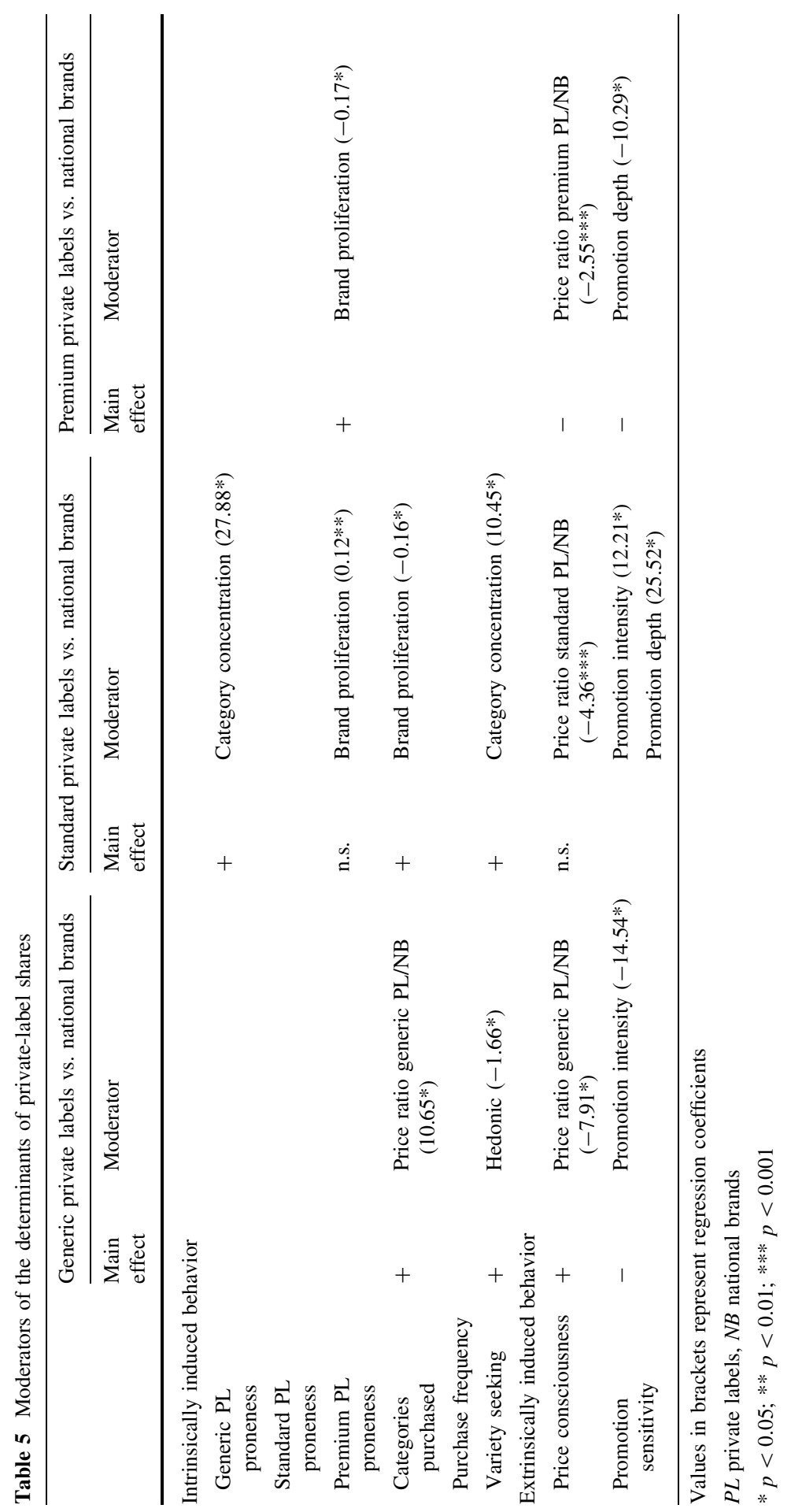


To account for product category characteristics, which might moderate the strength of an effect, we regress the z-scores of the independent variables against the respective product category characteristics (see Sethuraman and Gielens 2014, for more details). Therefore, for example, promotion intensity (as a product category characteristic) is used as an independent variable, and the z-score of promotion sensitivity (representing the direct effect) is applied as a dependent variable. Table 5 provides an overview of the product category characteristics, for which we found significant moderating effects.

Finally, hypothesis tests that use large samples can make even small effects statistically significant. Therefore, in accordance with Yao et al. (2009), we estimated our model with ten randomly drawn subsamples, each with $50 \%$ of the observations, to validate our model. These results are largely consistent with our main findings and thus support their robustness. The only exception is that we could not confirm a negative, significant effect of promotion sensitivity on generic privatelabel share, as only $30 \%$ of the subsamples reveal a significant effect in this same direction.

\subsection{Results}

\subsubsection{Intrinsically induced behavior}

Private-label proneness by tier In line with $\mathrm{H} 1$, private-label proneness for a certain quality tier positively influences private-label share in this tier. Specifically, generic $(\mathrm{z}=80.85, p<0.001)$, standard $(\mathrm{z}=33.81, p<0.001)$, and premium $(\mathrm{z}=18.57$, $p<0.001)$ private-label proneness all reveal significant effects on their respective tier shares. The effect is consistent across all categories and quality tiers, except that premium private-label proneness has a non-significant effect in the pralines category. These strongly consistent results confirm that consumers are private-label tier prone, regardless of specific product categories and that the effect can be generalized to all private-label tiers.

Adjacent private-label tier proneness In line with $\mathrm{H} 2$, we find that generic privatelabel proneness positively influences standard private-label share $(\mathrm{z}=26.26$, $p<0.001)$ and standard private-label proneness positively influences the generic $(\mathrm{z}=17.05, p<0.001)$ and premium $(\mathrm{z}=5.82, p<0.001)$ private-label shares. However, premium private-label proneness does not have a significant effect on the standard private-label share $(\mathrm{z}=.84, p>0.05)$, so that we cannot confirm $\mathrm{H} 2 \mathrm{c}$.

The effects of adjacent tier proneness are largely consistent across product categories for the generic and standard private labels. For example, regarding the effect of standard private-label proneness on generic private-label share $(\mathrm{H} 2 \mathrm{~b})$, the mayonnaise and mustard category is the only one that does not reveal a significant effect. For the effect of generic private-label proneness on standard private-label share $(\mathrm{H} 2 \mathrm{a})$, only the chocolate and frozen venison and poultry categories fail to exhibit a significant effect.

In contrast, these adjacent tier proneness effects are less pronounced across categories for the standard and premium private labels. For example, for ice cream, 
the effect of premium private-label proneness on standard private-label share $(\mathrm{H} 2 \mathrm{c})$ is negative; only two categories (vinegar and pralines) reveal a positive effect. The effect of standard private-label proneness on the premium private-label share $(\mathrm{H} 2 \mathrm{~d})$ is significant in only four categories (chocolate, mayonnaise and mustard, ice cream, and frozen venison and poultry). These weak and non-significant effects might arise because premium private labels generally are positioned differently compared to the traditional private labels that consumers perceive as inferior quality alternatives to national brands (Hoch 1996).

Overall, private-label tier proneness affects the adjacent private-label tier shares for the relationships between generic and standard private labels, but the effect is weaker or non-significant for the relationship between standard and premium private labels. In addition, the negative effects of premium private-label proneness on generic private-label share $(\mathrm{z}=-5.47, p<0.001)$ and of generic private-label proneness on premium private-label share $(\mathrm{z}=-4.90, p<0.001)$ highlight the contrary positioning between these two tiers. Generally, the results are in accordance with the effects of adjacent private-label proneness on the comparative shares of different private labels (see Table 4). That is, standard private-label proneness has inconsistent effects on premium private-label share compared to generic private-label share: it is positive for mayonnaise and mustard and frozen venison and poultry, negative for desserts, but non-significant generally across the categories $(\mathrm{z}=0.85, p>0.05)$. These results are indicative of the mid-tier positioning of standard private labels.

Relationship intensity In line with $\mathrm{H} 3$, consumers who bought a higher number of different product categories exhibit a higher private-label share, as indicated by the $\mathrm{z}$-scores for generic $(\mathrm{z}=6.85, p<0.001)$, standard $(\mathrm{z}=6.37, p<0.001)$, and premium $(\mathrm{z}=3.64, p<0.001)$ private labels.

However, for $\mathrm{H} 4$, in which we proposed that higher purchase frequency is associated with a higher share of generic, standard, and premium private labels, we determine effects only on generic private-label share $(\mathrm{z}=3.88, p<0.001)$ and not on standard $(\mathrm{z}=1.12, p>0.05)$ or premium $(\mathrm{z}=-1.45, p>0.05)$ private-label shares. Thus, the two measures of relationship intensity (i.e., more product categories purchased and more frequent purchases) appear to have different implications for private-label share.

According to Reinartz et al. (2008), cross-buying is associated with a greater affinity toward the firm. As expected, we find that consumers, who are more engaged into cross buying, prefer the retailer's entire private-label portfolio and especially its higher quality private-label tiers. This is also reflected in Table 4, where the number of categories purchased has a positive effect on premium privatelabel share compared to generic private-label share $(\mathrm{z}=2.15, p<0.05)$.

However, the effect of purchase frequency can be interpreted differently. We propose that consumers who exhibit a high purchase frequency at a certain retailer do most of their grocery shopping at this single retailer. Yet, most consumers purchase from more than one retailer and distribute their purchases across different retail formats (Ailawadi and Keller 2004; Bustos-Reyes and González-Benito 2008; Martos-Partal et al. 2015). Conventional supermarkets might offer generic private 
labels to remove consumers' motivation to make additional shopping trips to discounters and a high purchase frequency might signal that a consumer does not feel the need to purchase at a discounter to pay the lowest price. This effect is in line with the effects of purchase frequency across private-label tiers (see Table 3). Furthermore, purchase frequency has a significant negative effect on the premium private-label share compared to the generic private-label share $(\mathrm{z}=-2.49$, $p<0.05$ ), which might indicate that consumers with high purchase frequency address their need for low-priced products by purchasing generic private labels (see Table 4).

Still, we caution that our sample might be biased in relation to this effect, because we consider only the consumers who buy at least once every two months and thereby exclude intermittent consumers.

Variety seeking According to H5, we expect variety-seeking behavior to have a positive effect on private-label shares. Consistent with this hypothesis, varietyseeking behavior drives generic $(\mathrm{z}=14.8, p<0.001)$ and standard $(\mathrm{z}=12.76$, $p<0.001)$ private-label share. However, we cannot confirm H5c because varietyseeking behavior does not relate significantly to premium private-label share $(\mathrm{z}=1.78, p>0.05)$. Thus, the effect of variety seeking clearly is positive on the generic and standard quality levels, whereas we see no significant effect at the premium-quality level. Existing literature on private labels similarly offers unclear findings about whether variety seeking relates positively or negatively to the purchase of private labels (Ailawadi et al. 2001; Baltas 1997; ter Braak et al. 2014). In our study, variety seeking has a rather strong influence. With greater variety seeking, consumers are more likely to buy private labels instead of national brands, particularly generic and standard private labels. These results support Fader and Lodish's (1990) argument that variety seeking is associated with relatively lower priced products.

\subsubsection{Extrinsically induced behavior}

Price consciousness: In line with $\mathrm{H6a}$ and H6c, price consciousness generally leads to a higher generic private-label share $(\mathrm{z}=5.73, p<0.001)$ but a lower premium private-label share $(\mathrm{z}=-4.42, p<0.001)$ (see Table 3$)$. It does not have a significant effect on the share of standard private labels $(\mathrm{z}=1.17, p>0.05)$, so that we cannot confirm H6b. Price-conscious consumers seemingly prefer the lowest priced private-label tier and are not willing to pay a premium for a medium quality tier. Standard private labels are not always priced below national brands. In our study, the standard private labels in four categories were more expensive on average than the national brands (see Table 2). In two categories with significant positive effects (pralines and ice cream), the standard private labels are priced below national brands, whereas in one category that shows a negative significant effect (vinegar), they are priced above national brands. Meanwhile, premium private-label brands generally are more expensive than national brands (i.e., in ten categories with available premium private labels in the first 12 months of the sample; see 
Table 2), so we expected and find that price consciousness has a negative effect on premium private-label share.

The effects of price consciousness on the share of private labels relative to one another are also in line with our predictions (see Table 4): price-conscious consumers are less prone to buy standard $(\mathrm{z}=-3.34, p<0.001)$ and premium $(\mathrm{z}=-6.05, p<0.001)$ tiers compared to generic private labels. Moreover, they are less prone to buy premium private labels compared to standard private labels $(\mathrm{z}=-4.16, p<0.001)$.

Promotion sensitivity The $\mathrm{z}$-scores of generic $(\mathrm{z}=-2.56, p<0.05)$, standard $(\mathrm{z}=-3.28, p<0.01)$, and premium $(\mathrm{z}=-3.91, p<0.001)$ private labels support our prediction in $\mathrm{H} 7$ that promotion sensitivity has a negative effect on private-label shares. However, most of the individual product categories reveal no significant effect of promotion sensitivity on private-label share (see Table 3) and our robustness check for the sample size offers some inconsistent effects for promotion sensitivity.

Regarding the effects of promotion sensitivity on the relative shares of private labels, we find that promotion-sensitive consumers are less prone to buy premium private labels compared to generic $(\mathrm{z}=-3.41, p<0.001)$ or standard $(\mathrm{z}=-2.21$, $p<0.05$ ) private labels (see Table 4 ). However, promotion sensitivity does not appear to exert any influence with regard to the share of generic private labels compared to standard private labels $(\mathrm{z}=-1.52, p>0.05)$.

\subsubsection{Moderating product category characteristics}

Consumption occasion We find that the positive effect of variety seeking on generic private-label share weakens in hedonic product categories $(\beta=-1.66, p<0.05)$. Thus, we suggest that the benefits consumers derive from variety seeking diminish by the social risk associated with consuming such categories.

Price ratio The effect of the number of product categories purchased on generic private-label share is positively moderated by the price ratio between generic private labels and national brands $(\beta=10.65, p<0.05)$. Therefore, the positive effect of relationship intensity on generic private-label share compared to national brands becomes even stronger for product categories with a small price gap between generic private labels and national brands. As mentioned before, the coefficients of the moderating effects of generic and premium private labels must be interpreted differently: for generic private labels, a low price gap corresponds to a high price ratio. Generic private labels are priced below national brands in all categories, so that a high price gap leads to a low price ratio. The opposite holds for premium private labels, which are generally priced higher than national brands.

We proposed that price consciousness might be moderated by product category characteristics, including the price ratio in the categories. Our finding regarding the effect of price consciousness on standard private labels, which depends partially on whether the price gap with national brands is positive or negative, offers some support for our proposition. Despite the non-significant effect of price consciousness on standard private-label shares compared to national brands, the price ratio has a 
highly significant moderating influence $(\beta=-4.36, \mathrm{p}<0.001)$. The positive effect of price consciousness on the generic private-label share becomes weaker as the price ratio between private labels and national brands in a given category becomes larger $(\beta=-7.91, p<0.05)$. Thus, the effect of price consciousness is weaker in categories with small price gaps between generic private labels and national brands. For premium private labels, we find that the negative effect of price consciousness gets reinforced by the price ratio $(\beta=-2.55, p<0.001)$. Thus, when premium private labels are relatively more expensive compared to national brands, priceconscious consumers are less likely to buy them.

Promotion intensity Martos-Partal et al. (2015) do not find that promotion sensitivity has any significant effect on private-label share in terms of generic, standard, and premium private-label tiers. We explain this difference in results with the heterogeneity across product categories. Sinha and Batra (1999) even state that national brand marketers should consider how different product categories might be affected differently by cuts in promotion budgets. Thus, managers cannot simply allocate these budgets equally because of the category-level heterogeneity in consumers' promotion sensitivity.

We find that the negative effect of promotion sensitivity on generic private-label shares is strengthened by a category's promotion intensity $(\beta=-14.54, p<0.05)$. Even though the main effect of price consciousness on standard private-label share is not significant, we reveal that the effect is moderated by promotion intensity $(\beta=12.21, p<0.05)$. Generally, standard private labels are promoted more often compared to generic private labels in our study. Price-conscious consumers therefore prefer to buy standard private labels compared to generic private labels in product categories with a high promotion intensity.

Promotion depth Similar to the promotion intensity's moderating effect on the effect of price consciousness on standard private-label share, promotion depth (i.e., the average amount of savings) also reveals a positive influence $(\beta=25.52, p<0.05)$. Notably, the negative effect of promotion sensitivity on generic private-label share is not influenced by promotion depth, whereas promotion depth moderates the negative effect of promotion sensitivity on premium private-label share $(\beta=-10.29, p<0.05)$.

Brand proliferation We find that brand proliferation indicates two significant moderating effects regarding the drivers of standard private-label share. On the one hand, the non-significant effect of premium private-label proneness on standard private-label share is positively influenced by brand proliferation $(\beta=0.12$, $p<0.01)$. Accordingly, in product categories with a high number of competing brands, consumers who are susceptible to buying premium private labels are more likely to buy standard private labels compared to national brands. Consumers might reduce their cognitive effort, especially in product categories with a high degree of choice complexity, and therefore rely on their general experience with private-label tiers, even if they are positioned differently. 
On the other hand, brand proliferation negatively influences the effect of categories purchased (i.e., relationship intensity) on standard private-label share $(\beta=-0.16, p<0.05)$. We proposed that relationship intensity with the retailer has a positive effect on private-label share, because consumers with such relationships are confronted with the retailer's private-label brands more often and are more likely to include them in their consideration sets. The negative effect of brand proliferation might reveal that private labels get lost in product categories where consumers are confronted with many brands, especially when the private label is closely positioned to national brands.

Brand proliferation also negatively moderates the effect of premium private-label proneness on premium private-label share $(\beta=-0.17, p<0.05)$. Retailers often use premium private labels to close assortment gaps (Kumar and Steenkamp 2007). We suggest that positioning a brand as distinct becomes more difficult in product categories that have many different brands. In particular, premium private labels that are positioned close to or above national brands might struggle to retain consumers who have been prone to buying premium private labels across different product categories.

Category concentration The market power of national brands is generally higher in product categories where a small number of brands accounts for a major proportion of category sales (Steenkamp and Geyskens 2014). The general conditions for private labels might therefore be better in fragmented markets (ter Braak et al. 2014). Nevertheless, Dhar and Hoch (1997) claim that the positioning of private labels compared to national brands is more easily achieved in product categories where the market share is distributed across only a few national brands (e.g., through an imitation strategy).

In our study, the positive effect of generic private-label proneness on standard private-label share is strengthened by category concentration $(\beta=27.88, p<0.05)$. Here, the positioning of generic private labels in terms of a low-cost alternative to the dominating national brands might be especially successful. Generic private labels might therefore create a spillover effect on the success of standard private labels that exhibit a much smaller degree of differentiation compared to national brands.

Category concentration also strengthens the positive effect of variety seeking on standard private-label share $(\beta=10.45, p<0.05)$. In product categories that have only a few dominating national brands, standard private labels might provide a promising opportunity to fulfill consumers' variety-seeking needs.

\subsubsection{Control variables}

Family households seem to prefer generic private labels to national brands $(\mathrm{z}=3.95, p<0.001)$. That is, consumers purchasing many baby products are more likely to buy generic private labels instead of national brands. The results regarding shopping on the weekend also are generally positive regarding the share of generic $(\mathrm{z}=3.87, p<0.001)$ and premium $(\mathrm{z}=2.21, p<0.05)$ private labels. 


\section{Discussion}

\subsection{Theoretical implications}

Our study reveals that private-label tiers and product categories play an important role in private-label purchasing behavior. Previous research claims that references to private labels as a whole are too simplistic (Martos-Partal et al. 2015). Similarly, our study indicates heterogeneous effects across product categories and privatelabel tiers. In the following, we address the three major questions, which we raised at the start of this article.

Do consumers reveal similarities in their preference for private labels across categories and private-label tiers?

Our results show that consumers who exhibit a high level of general private-label proneness reveal a propensity to purchase private labels in a given category. The effect of private-label proneness is generally not limited to a specific product category. In addition, our strongly consistent findings indicate that this effect, as demonstrated for low-priced private labels by Hansen et al. (2006), can be generalized to all private-label tiers.

Does consumers' private-label proneness for a certain private-label tier affect their private-label preference in other tiers?

We find that consumers' private-label tier proneness affects adjacent privatelabel tier shares for generic and standard private labels, but we find weaker and nonsignificant effects with regard to standard and premium private-label tiers. This difference might reflect the non-traditional positioning of private labels in the premium-quality tier. Similarly, we find a negative effect on private-label brands that have a diametrically opposed positioning (e.g., generic vs. premium). These results are also in line with Sethuraman and Cole's (1999) claim that brand switching is more likely between adjacent tiers.

Ultimately, we propose that the degree to which consumers treat different private-label tiers as one or different mental categories is strongly associated with the degree to which private-label brands are positioned as traditional private labels (i.e., best price and lower quality offers).

Do category characteristics moderate private-label preference factors?

Our results show that product category characteristics moderate factors that drive private-label preferences, which affirms the need for private-label research to consider product category characteristics. For example, the price ratio of private labels to national brands moderates the relationship between price consciousness and private-label shares. Further category characteristics, which moderate the determinants of private-label shares are the degree to which a product category is perceived as hedonic, the promotion intensity and depth, category concentration, and brand proliferation. 
Beyond these major questions, we reveal that relationship intensity, variety seeking, price consciousness, and promotion sensitivity are key determinants of the propensity to purchase private labels. Yet, these effects are not always consistent across product categories or private-label tiers. Our results are in line with previous studies (e.g., Ailawadi et al. 2001) revealing that price consciousness is a key consumer characteristic, which explains purchasing behavior, but only with regard to generic and premium private-label tiers. The effects of price consciousness on standard private labels are less clear and more ambiguous. Previous research claims that variety seeking also has an unclear role regarding the propensity to purchase private labels (Ailawadi et al. 2001; Baltas 1997; ter Braak et al. 2014). Our study supports the suggestion of Fader and Lodish (1990) that variety seeking might be associated with relatively lower priced products. Specifically, generic and standard private-label shares are positively driven by variety-seeking behavior, but such behavior has no significant effect on premium private-label share. The effect of purchase frequency on preferences for private labels indicates mixed results across private-label tiers and product categories.

Overall, we show that private-label tiers cannot be treated alike and purchasing behavior can differ across different tiers. Moreover, product category characteristics influence private-label purchasing.

\subsection{Managerial implications}

Because we include both, intrinsically and extrinsically induced measures of consumer behavior related to private-label purchasing propensity, our study offers insights that managers can use to react to intrinsically induced measures (e.g., through targeted communication) and to proactively influence extrinsically induced measures in the short term (e.g., promotions and price cuts) to achieve their objectives.

We consider private-label tier proneness as an intrinsically induced measure that is driven by consumers' willingness to continue purchasing a certain brand. We find that private-label tier proneness has a strong, consistent effect on private-label tier share in different product categories. The results emphasize the advantages of a uniform private-label branding strategy across product categories. Further, retailers might use these insights in their cross-selling efforts. If they find that consumers are prone to certain private-label tiers, they should seek to determine in which product categories these consumers have not yet purchased private labels. Communication measures enticing consumers to try products in the private-label tier to which they are most prone but in product categories in which they have not yet bought private labels or in which they buy national brands (which induce a certain household demand), might leverage the retailers' private-label share.

Our findings indicate that consumers who have a proneness for a certain privatelabel tier have a propensity to buy adjacent private-label tiers. Because ter Braak et al. (2014) show that higher quality private-label tiers provide retailers with higher margins, we recommend that retailers try to entice consumers who are prone to generic private labels to also try standard-tier products, or those who are prone to standard private labels, to try premium versions. The chances that the retailer can 
upsell its private-label portfolio are good in these cases. However, private-label tier proneness has a negative effect on consumers' propensity to buy distant private labels (i.e., generic to premium private-label products in certain categories), so that upselling is likely to fail in this case. Our results also highlight the risk that consumers prone to purchasing standard private labels might migrate to a generic tier. Nevertheless, this downward migration risk does not appear between premium and standard private labels.

We consider price-related and promotion-related measures as extrinsically induced, which means that the retailer can respond to them in the short term. Changes in prices and in promotion intensity can leverage consumers' price consciousness and promotion sensitivity and we show that managing the price gap between private labels and national brands is essential for increasing private-label shares and margins. On the one hand, our results show that the share of generic private labels can be increased through a high price gap (i.e., a low price ratio) between national brands and generic private labels among price-conscious consumers. On the other hand, retailers need to be cautious when pricing standard private labels. If they are priced close to or even above national brands, these standard private-label brands cannot appeal effectively to price-conscious consumers.

We find that promotion sensitivity generally has a negative effect on private-label share across all quality tiers and thus, promotions can decrease the market share of private labels (Sethuraman and Gielens 2014). The negative effect is emphasized for generic private-label shares in product categories that have a high promotion intensity, while the negative effect for premium private-label shares is emphasized in product categories that have a high promotion depth. Surprisingly, we do not find that the effect of promotion sensitivity on generic private-label share is emphasized by promotion depth or that promotion sensitivity is emphasized by promotion intensity for premium private-label brands. According to ter Braak et al. (2014), retailers introduce premium private-label brands less often in product categories that have a high promotion intensity, whereas promotion depth does not play any role. Our study indicates that premium private labels are bought less often by promotionsensitive consumers in categories, which have a high promotion depth, while promotion intensity does not play a role. Retailers should therefore adapt their strategy accordingly. From a manufacturer's perspective, the market share of national brands that compete with generic private labels can be increased through high promotion intensity, while the market share of national brands that compete with premium private-label brands can be increased through a high promotion depth.

Although price consciousness drives generic private-label share, we do not find a significant direct effect for standard private labels. Nevertheless, the latter is positively moderated by promotion intensity and depth. If retailers aim to increase the market share of their standard private labels, they should emphasize their promotion efforts (i.e., promotion depth and intensity). Price-conscious consumers might then switch from generic private labels to standard private labels.

The degree to which product categories are perceived as hedonic limits privatelabel success. In hedonic product categories, the strong effect of variety seeking on 
generic private-label share diminishes, likely because hedonic products often are consumed in public, but generic private labels bear a high social risk in this regard.

\subsubsection{Limitations and further research}

Our transaction data come from a loyalty program and it should be kept in mind that loyalty programs might not include every purchase incident. Because of their privacy concerns, some consumers might find that the cost of using a loyalty card is greater than its benefits (Challagalla et al. 2009). Some consumers might therefore use their loyalty card only if their purchases exceed some amount. Furthermore, members of loyalty programs might be more price-conscious than non-members and their enrollment in the program reflects their desire to save money.

The loyalty program data also might be biased toward consumers with higher purchase frequencies and volumes, who can achieve rewards more readily and thus have more incentives to become a member (Leenheer et al. 2007). In our sample of loyalty program members who conducted at least one purchase every 2 months over a 2-year period, we investigated only regular consumers. Excluding occasional consumers could produce some biased estimates, in that consumers with a high purchase frequency often are more price-sensitive and have more sharply defined preferences for national brands than consumers with a low purchase frequency (Andrews and Currim 2005; Kim and Rossi 1994).

We also cannot link the individual purchasing behavior data in our sample with any sociodemographic variables. We use proxies (family household and weekend purchasers), but further research should include additional sociodemographic variables, such as age and household income, to control for their potential effects. However, because demographic variables are often poor predictors of consumer preferences (e.g., Chintagunta 1994; Hansen et al. 2006; Rossi et al. 1996), this limitation might be less of a concern.

We used a sample of business students to determine product category characteristics, who might not be representative of regular consumers. Nevertheless, students previously have been used as informants-for example, to evaluate the credibility, risk, and quality of a brand (e.g., Erdem and Swait 1998) or in studies on private-label research (e.g., Sprott and Shimp 2004). Thus, we posit that students buy the product categories in our study and are able to evaluate them.

Some unobserved consumer heterogeneity might reside in the relationship between the behavioral measures and the private-label shares in our study. Modeling this heterogeneity across consumers and categories would complicate the model, but it is another fruitful area for further research.

In addition, considering our finding that product categories strongly influence consumers' private-label purchasing behavior, investigations of product categories at even more disaggregated levels could help confirm whether SKUs of national brands and different private-label tiers are substitutable. Furthermore, our study is limited to 12 product categories with different private-label tiers and future research could examine additional categories in order to reveal more reliable moderating effects. 
In many cases, product choices from multiple categories are interdependent (Hruschka 2014), and despite empirical evidence that product category characteristics influence consumers' private-label choices, few studies have included crosscategory effects. We address these interdependencies by considering consumers' private-label proneness across categories and within categories, aggregated across all purchase incidents. Nevertheless, buying private labels in a certain product category still might influence the purchases of private labels in complementary product categories during a single purchase occasion. This question represents another interesting avenue for research.

Beyond private-label tiers and product categories, a product's intended consumption situation (e.g., private vs. public) might offer another source of heterogeneity. Further research could examine whether the intended consumption situation affects the drivers of private-label purchasing.

Supermarket shelf displays affect consumers' evaluation of brands (Chandon et al. 2009) and different space allocations could explain some of the differences in private-label purchasing behavior we find across categories. Therefore, we call for research that examines, for example, whether the proximity of national brands and private labels on shelves influences private-label purchasing behavior.

Finally, our results unveil several product category characteristics, which influence the success of different private-label tiers. Interviews with experts from the industry revealed, that supermarket chains do not necessarily seek to increase their generic private-label share because of their inferior margins compared to other private-label tiers and national brands. Instead, generic private labels are often used as a measure to compete against discounters, so that consumers do not satisfy their demand for particular categories or products at different retailers. Apart from this strategic use of private labels, retailers might use them as a strategic instrument in channel management. Here, power-dependent relationships with manufacturers play a central role (Krafft et al. 2015). By altering certain product category characteristics (e.g., brand proliferation, promotion intensity, and depth), retailers and manufacturers might improve their respective power in the relationship. Further research could investigate how such product-category-related measures can be used strategically to successfully manage the distribution channel from both perspectives.

Acknowledgments The authors thank the two anonymous reviewers for comments that greatly improved the article. They also thank Manfred Krafft for his useful feedback.

Open Access This article is distributed under the terms of the Creative Commons Attribution 4.0 International License (http://creativecommons.org/licenses/by/4.0/), which permits unrestricted use, distribution, and reproduction in any medium, provided you give appropriate credit to the original author(s) and the source, provide a link to the Creative Commons license, and indicate if changes were made.

\section{References}

Ailawadi KL, Keller KL (2004) Understanding retail branding: conceptual insights and research priorities. J Retail 80(4):331-342

Ailawadi KL, Neslin SA, Gedenk K (2001) Pursuing the value-conscious consumer: store brands versus national brand promotions. J Mark 65(1):71-89 
Ailawadi KL, Pauwels K, Steenkamp J-BEM (2008) Private-label use and store loyalty. J Mark 72(6):19-30

Andrews RL, Currim IS (2005) An experimental investigation of scanner data preparation strategies for consumer choice models. Int J Res Mark 22(3):319-331

Andrews RL, Srinivasan TC (1995) Studying consideration effects in empirical choice models using scanner panel data. J Mark Res 32(1):30-41

Baltas G (1997) Determinants of store brand choice: a behavioral analysis. J Prod Brand Manag 6(5):315-324

Baltas G, Doyle P, Dyson P (1997) A model of consumer choice for national vs private label brands. J Oper Res Soc 48(10):988-995

Batra R, Sinha I (2000) Consumer-level factors moderating the success of private label brands. J Retail 76(2):175-191

Bearden WO, Etzel MJ (1982) Reference group influence on product and brand purchase decisions. J Consum Res 9(2):183-194

Bell DR, Chiang J, Padmanabhan V (1999) The decomposition of promotional response: an empirical generalization. Mark Sci 18(4):504-526

Blattberg RC, Wisniewski KJ (1989) Price-induced patterns of competition. Mark Sci 8(4):291-309

Buis M (2008) Fmlogit: Stata module fitting a fractional multinomial logit model by quasi maximum likelihood. http://EconPapers.repec.org/RePEc:boc:bocode:s456976. Accessed June 2015

Burton S, Lichtenstein D, Netemeyer R, Garretson J (1998) A scale for measuring attitude toward private label products and an examination of its psychological and behavioral correlates. J Acad Mark Sci 26(4):293-306

Bustos-Reyes CA, González-Benito Ó (2008) Store and store format loyalty measures based on budget allocation. J Bus Res 61(9):1015-1025

Challagalla G, Venkatesh R, Kohli AK (2009) Proactive postsales service: when and why does it pay off? J Mark 73(2):70-87

Chandon P, Hutchinson JW, Bradlow ET, Young SH (2009) Does in-store marketing work? Effects of the number and position of shelf facings on brand attention and evaluation at the point of purchase. J Mark 73(6):1-17

Chintagunta PK (1994) Heterogeneous logit model implications for brand positioning. J Mark Res 31(2):304-311

Chitturi R, Raghunathan R, Mahajan V (2008) Delight by design: the role of hedonic versus utilitarian benefits. J Mark 72(3):48-63

Cohen JB, Basu K (1987) Alternative models of categorization: toward a contingent processing framework. J Consum Res 13(4):455-472

DelVecchio D, Heath TB (2008) An experimental test of brand insulation against competitor attacks: effects of consumer heterogeneity and residual desire. Psychol Mark 25(10):944-960

Dhar SK, Hoch SJ (1997) Why store brand penetration varies by retailer. Mark Sci 16(3):208-227

Dodson JA, Tybout AM, Sternthal B (1978) Impact of deals and deal retraction on brand switching. J Mark Res 15(1):72-81

Dunne D, Narasimhan C (1999) The new appeal of private labels. Harvard Bus Rev 77(3):41-52

Erdem T, Swait J (1998) Brand equity as a signaling phenomenon. J Consum Psychol 7(2):131-157

Erdem T, Zhao Y, Valenzuela A (2004) Performance of store brands: a cross-country analysis of consumer store-brand preferences, perceptions, and risk. J Mark Res 41(1):86-100

Fader PS, Lodish LM (1990) A cross-category analysis of category structure and promotional activity for grocery products. J Mark 54(4):52-65

Geyskens I, Gielens K, Gijsbrechts E (2010) Proliferating private-label portfolios: how introducing economy and premium private labels influences brand choice. J Mark Res 47(5):791-807

Gielens K (2012) New products: the antidote to private label growth? J Mark Res 49(3):408-423

Hansen K, Singh V, Chintagunta P (2006) Understanding store-brand purchase behavior across categories. Mark Sci 25(1):75-90

Hoch SJ (1996) How should national brands think about private labels? Sloan Manag Rev 37(2):89-102

Homburg C, Schwemmle M, Kuehnl C (2015) New product design: concept, measurement, and consequences. J Mark 79(3):41-56

Hruschka H (1986) Market definition and segmentation using fuzzy clustering methods. Int J Res Mark 3(2):117-134

Hruschka H (2014) Analyzing market baskets by restricted Boltzmann machines. OR Spectr 36(1):209-228 
Kapferer J-N, Laurent G (1993) Further evidence on the consumer involvement profile: five antecedents of involvement. Psychol Mark 10(4):347-355

Kaufmann A (1975) Introduction to the theory of fuzzy subsets. Academic Press, New York

Keller KO, Dekimpe MG, Geyskens I (2016) Let your banner wave? Antecedents and performance implications of retailers' private-label branding strategies. J Mark 80(4):1-19

Kim B-D, Rossi P (1994) Purchase frequency, sample selection, and price sensitivity: the heavy-user bias. Mark Lett 5(1):57-67

Koschate-Fischer N, Cramer J, Hoyer WD (2014) Moderating effects of the relationship between private label share and store loyalty. J Mark 78(2):69-82

Krafft M, Goetz O, Mantrala M, Sotgiu F, Tillmanns S (2015) The evolution of marketing channel research domains and methodologies: an integrative review and future directions. J Retail 91(4):569-585

Kumar N, Steenkamp J-BEM (2007) Private label strategy: how to meet the store brand challlange. Harvard Business School Press, Boston

Lal R (1990) Price promotions: limiting competitive encroachment. Mark Sci 9(3):247-262

Lamey L, Deleersnyder B, Steenkamp J-BE, Dekimpe MG (2012) The effect of business-cycle fluctuations on private-label share: what has marketing conduct got to do with it? J Mark 76(1):1-19

Leenheer J, Van Heerde HJ, Bijmolt THA, Smidts A (2007) Do loyalty programs really enhance behavioral loyalty? An empirical analysis accounting for self-selecting members. Int J Res Mark 24(1):31-47

Lourenço CJ, Gijsbrechts E, Paap R (2015) The impact of category prices on store price image formation: an empirical analysis. J Mark Res 52(2):200-216

Manzur E, Olavarrieta S, Hidalgo P, Farías P, Uribe R (2011) Store brand and national brand promotion attitudes antecedents. J Bus Res 64(3):286-291

Martos-Partal M, González-Benito O, Fustinoni-Venturini M (2015) Motivational profiling of store brand shoppers: differences across quality tiers. Mark Lett 26(2):187-200

Mazursky D, LaBarbera P, Aiello A (1987) When consumers switch brands. Psychol Mark 4(1):17-30

Mela CF, Gupta S, Lehmann DR (1997) The long-term impact of promotion and advertising on consumer brand choice. J Mark Res 34(2):248-261

Mervis CB, Rosch E (1981) Categorization of natural objects. Annu Rev Psychol 32(1):89-115

Mullahy J (2015) Multivariate fractional regression estimation of econometric share models. J Econometr Methods 4(1):71-100

Nenycz-Thiel M, Romaniuk J (2009) Perceptual categorization of private labels and national brands. J Prod Brand Manag 18(4):251-261

Nijs VR, Srinivasan S, Pauwels K (2007) Retail-price drivers and retailer profits. Mark Sci 26(4):473-487

Noble CH, Walker BA (1997) Exploring the relationships among liminal transitions, symbolic consumption, and the extended self. Psychol Mark 14(1):29-47

Palmeira MM, Thomas D (2011) Two-tier store brands: the benefic impact of a value brand on perceptions of a premium brand. J Retail 87(4):540-548

Pan Y, Lehmann DR (1993) The influence of new brand entry on subjective brand judgments. J Consum Res 20(1):76-86

Papke LE, Wooldridge JM (1996) Econometric methods for fractional response variables with an application to 401(k) plan participation rates. J Appl Econometr 11(6):619-632

Private Label Manufacturers Association (2016) PLMA's 2016 private label yearbook. http://plma.com/ share/press/resources/plma2016yb_comb_rpt.pdf. Accessed Aug 2016

Quelch JA, Harding D (1996) Brands versus private labels: fighting to win. Harv Bus Rev 74(1):99-109

Raghunathan R, Corfman KIM (2006) Is happiness shared doubled and sadness shared halved? Social influence on enjoyment of hedonic experiences. J Mark Res 43(3):386-394

Ragin CC (2009) Redesigning social inquiry: fuzzy sets and beyond. University of Chicago Press, Chicago

Raju JS, Sethuraman R, Dhar SK (1995) The introduction and performance of store brands. Manag Sci 41(6):957-978

Reinartz W, Thomas JS, Bascoul G (2008) Investigating cross-buying and customer loyalty. J Interact Mark 22(1):5-20

Richardson PS, Jain AK, Dick A (1996) Household store brand proneness: a framework. J Retail 72(2):159-185

Rosenthal R (1991) Meta-analytic procedures for social research. Sage, Thousand Oaks 
Rossi PE, McCulloch RE, Allenby GM (1996) The value of purchase history data in target marketing. Mark Sci 15(4):321-340

Schnittka O, Becker J-M, Gedenk K, Sattler H, Villeda IV, Völckner F (2015) Does chain labeling make private labels more successful? Schmalenbach Bus Rev 67(1):92-113

Seetharaman PB, Chib S, Ainslie A, Boatwright P, Chan T, Gupta S, Mehta N, Rao V, Strijnev A (2005) Models of multi-category choice behavior. Mark Lett 16(3-4):239-254

Sethuraman R (1992) The effect of marketplace factors on private label penetration in grocery products. Marketing Science Institute Report No 92-128 Cambridge, MA

Sethuraman R (1995) A meta-analysis of national brand and store brand cross-promotional price elasticities. Mark Lett 6(4):275-286

Sethuraman R (2009) Assessing the external validity of analytical results from national brand and store brand competition models. Mark Sci 28(4):759-781

Sethuraman R, Cole C (1997) Why do consumers pay more for national brands than for store brands? Marketing Science Institute Report No 97-126 Cambridge, MA

Sethuraman R, Cole C (1999) Factors influencing the price premiums that consumers pay for national brands over store brands. J Prod Brand Manag 8(4):340-351

Sethuraman R, Gielens K (2014) Determinants of store brand share. J Retail 90(2):141-153

Shocker AD, Ben-Akiva M, Boccara B, Nedungadi P (1991) Consideration set influences on consumer decision-making and choice: issues, models, and suggestions. Mark Lett 2(3):181-197

Sinha I, Batra R (1999) The effect of consumer price consciousness on private label purchase. Int J Res Mark 16(3):237-251

Smithson M (2012) Fuzzy set analysis for behavioral and social sciences. Springer Science \& Business Media, New York

Sprott DE, Shimp TA (2004) Using product sampling to augment the perceived quality of store brands. J Retail 80(4):305-315

Steenkamp J-BEM, Geyskens I (2014) Manufacturer and retailer strategies to impact store brand share: global integration, local adaptation, and worldwide learning. Mark Sci 33(1):6-26

Szymanowski M, Gijsbrechts E (2012) Consumption-based cross-brand learning: are private labels really private? J Mark Res 49(2):231-246

ter Braak A, Dekimpe MG, Geyskens I (2013) Retailer private-label margins: the role of supplier and quality-tier differentiation. J Mark 77(4):86-103

ter Braak A, Geyskens I, Dekimpe MG (2014) Taking private labels upmarket: empirical generalizations on category drivers of premium private label introductions. J Retail 90(2):125-140

The Nielsen Company (2014) The state of private label around the world. http://www.nielsen.com/ content/dam/corporate/us/en/reports-downloads/2014\%20Reports/state-of-private-label-around-theworld-nov-2014.pdf. Accessed June 2015

Till BD, Priluck RL (2000) Stimulus generalization in classical conditioning: an initial investigation and extension. Psychol Mark 17(1):55-72

Van Trijp HC, Hoyer WD, Inman JJ (1996) Why switch? Product category: level explanations for true variety-seeking behavior. J Mark Res 33(3):281-292

Viswanathan M, Childers TL (1999) Understanding how product attributes influence product categorization: development and validation of fuzzy set-based measures of gradedness in product categories. J Mark Res 36(1):75-94

Wakefield KL, Inman JJ (2003) Situational price sensitivity: the role of consumption occasion, social context and income. J Retail 79(4):199-212

Wu J, Rangaswamy A (2003) A fuzzy set model of search and consideration with an application to an online market. Mark Sci 22(3):411-434

Yao Y, Dresner M, Palmer J (2009) Private network EDI vs. Internet electronic markets: a direct comparison of fulfillment performance. Manag Sci 55(5):843-852

Zadeh LA (1965) Fuzzy sets. Inf Control 8(3):338-353

Zielke S, Dobbelstein T (2007) Customers' willingness to purchase new store brands. J Prod Brand Manag 16(2):112-121 